Check for updates

Cite this: J. Anal. At. Spectrom., 2017, 32, 1224

Received 17th March 2017 Accepted 25th April 2017

DOI: 10.1039/c7ja00096k

rsc.li/jaas

\section{Sample-in-waveguide geometry for TXRF sensitivity improvement $\dagger$}

\author{
Vitaly Panchuk, ${ }^{\text {abc }}$ Alexander Goydenko, ${ }^{a}$ Andrey Grebenyuk, ${ }^{\mathrm{c}}$ Sobir Irkaev, ${ }^{\mathrm{c}}$ \\ Andrey Legin, ${ }^{\text {ab }}$ Dmitry Kirsanov (DD *ab and Valentin Semenov ${ }^{\text {ac }}$
}

Total reflection X-ray fluorescence (TXRF) is a rapidly developing trace analysis method due to a number of advantages. It is a fast and multielemental method and does not require complex sample pretreatment. Nevertheless, there are certain drawbacks (especially in the environmental analysis) where TXRF sensitivity is not sufficient and employment of various preconcentration methods is required. The present study suggests a very simple procedure based on a planar waveguide technique, where the sample to be analyzed is placed directly into the waveguide. Waveguide construction is also simple and can be produced in any lab using two standard glass reflectors. Such an approach permits considerable improvement of the signal-to-noise ratio in a spectrum and allows for achievement of detection limits for e.g. $\mathrm{Cd}$ and $\mathrm{Hg}$ at $0.12 \mu \mathrm{g} \mathrm{L}^{-1}$ and $0.13 \mu \mathrm{g} \mathrm{L}^{-1}$ respectively.

\section{Introduction}

Total reflection X-ray fluorescence spectroscopy (TXRF) has gained wide acceptance as a convenient and effective tool for micro-analysis in numerous analytical tasks. Low detection limits, simultaneous quantification of several elements, and easy sample preparation make TXRF an attractive analytical instrument in materials science, ${ }^{\mathbf{1}}$ geology, ${ }^{\mathbf{2}}$ ecology, ${ }^{3}$ biology, etc.

Nevertheless, there are certain problems associated with TXRF and one of the major issues precluding further development of TXRF analytical applications is insufficient sensitivity. This problem is especially important in environmental and medical studies where low detection limits are often required.

A conventional way of increasing TXRF sensitivity is application of various methods for preliminary sample concentration. For example, liquid phase microextraction was applied, in ref. 5 for $\mathrm{Sb}$ (III) and $\mathrm{Sb}(\mathrm{v})$ quantification at the $\mu \mathrm{g} \mathrm{L}^{-1}$ level. It was suggested in ref. 6 to concentrate analytes $(\mathrm{Cu}, \mathrm{Co}, \mathrm{Ni}, \mathrm{Zn})$ in an anion-exchange membrane with subsequent analysis of the membrane with TXRF. Classical solid sorbents ${ }^{7}$ and nano-sized sorbents $^{8}$ can also be applied.

In addition to pre-concentration, TXRF sensitivity can be improved in an instrumental way - by increasing the signal-tonoise ratio. In certain cases (especially when analyte separation to diminish interference or to address certain valence forms is

${ }^{a}$ St. Petersburg State University, Institute of Chemistry, St. Petersburg, Russia. E-mail: d.kirsanov@gmail.com

${ }^{b}$ Laboratory of Artificial Sensory Systems, ITMO University, St. Petersburg, Russia ${ }^{c}$ Institute for Analytical Instrumentation RAS, St. Petersburg, Russia

$\dagger$ Electronic supplementary information (ESI) available. See DOI: 10.1039/c7ja00096k not required) such an increase can be sufficient to address an analytical task without sample pretreatment. The main reason for the background signal in X-ray spectroscopy is scattered radiation. Thus, materials with low scattering used as reflectors can decrease the background signal. In order to increase the analytical signal one has to increase the density of electromagnetic radiation focused on the sample by enhancing the power of the X-ray source; however this will lead to a proportional increase of the background signal as well. Another way to increase the X-ray density without increasing the power of the source is application of special X-ray optics, such as polycapillary optics, ${ }^{9}$ planar waveguides, ${ }^{10}$ and multilayer X-ray mirrors. ${ }^{11}$ Application of planar waveguides is the most prospective option from the point of view of sensitivity enhancement. Such waveguides are three-layer systems containing finely polished (surface roughness below tens of angstroms) parallel solid surfaces as upper and lower layers and a gas (e.g. ambient air) layer between them.

A standing wave characterized by high photon density is formed in the planar waveguide due to multiple repetitions of the total reflection of the incident wave. Normally such an approach is employed to form X-rays with insignificant angular divergence that are required for total reflection measurements. However, when the sample is placed into the layer between waveguides this leads to an enhancement of the analytical signal due to an increase of X-ray density compared to single reflection occurring in ordinary geometry with a standard sample carrier. This report is devoted to exploration of this opportunity of increasing TXRF sensitivity. A case study on the quantification of several heavy metals in aqueous solutions simulating surface waters was considered. 


\section{Experimental}

\subsection{TXRF measurements}

TXRF measurements were performed with a Rigaku Nanohunter spectrometer using a molybdenum anode X-ray tube and a silicon drift detector (SDD). According to the producer's specifications the distance between the sample and SDD element is $6 \mathrm{~mm}$. The Rigaku Nanohunter allows for tuning the excitation radiation grazing angle. Spectra were recorded at 50 $\mathrm{kV}$ voltage and $0.6 \mathrm{~mA}$ current with an accumulation time of $300 \mathrm{~s}$ for each sample. The incidence angle of excitation radiation was $0.1^{\circ}$ for all measurements performed in the conventional geometry.

\subsection{Waveguide}

Planar waveguides were constructed using standard soda lime glass reflectors for TXRF measurements with the following dimensions: $26 \times 76 \times 2 \mathrm{~mm}$ (width $\times$ length $\times$ height). Glass reflectors were from Matsunami Glass Ind., Ltd. (Japan) with surface roughness around 1-2 $\mathrm{nm}$. The sample to be analyzed was placed on the glass reflector and dried (lower waveguide layer). The upper layer of the waveguide consisted of two pieces (30 mm long each) of another glass reflector. These pieces were obtained by cutting the standard reflector and treating the place of cut with concentrated hydrofluoric acid to eliminate the edges. The two pieces were further placed on the surface of the lower waveguide layer in a way to ensure that the split between two pieces is right in front of the spectrometer detector (Fig. 1, bottom picture).

The distance between upper and lower waveguide layers was tuned by gluing double sided sticky tape on the long borders of the lower layer. The thickness of the tape was approximately 125 $\mu \mathrm{m}$. In order to determine the best conditions three waveguides with different thicknesses were made $(0,125$ and $250 \mu \mathrm{m})$. Zero thickness refers to the case when no tape was placed between

\section{Conventional approach}

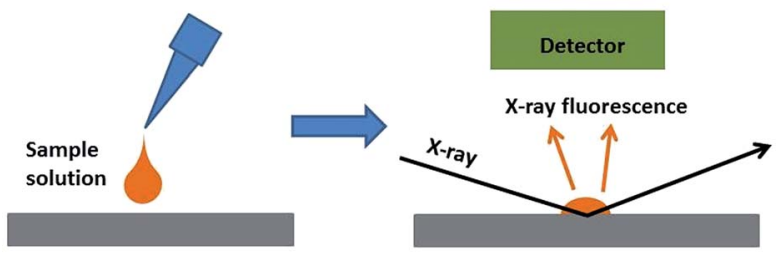

Suggested approach

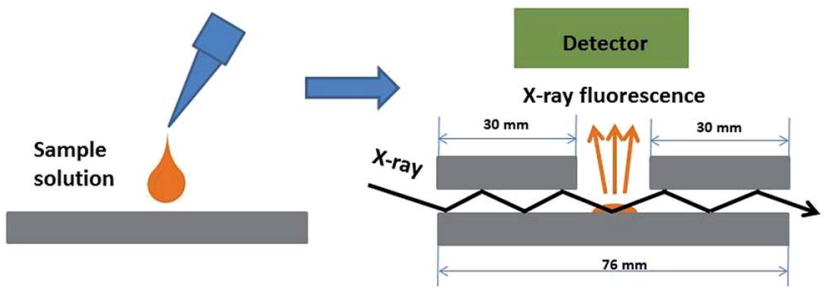

Fig. 1 The schematic of the suggested sample-in-a-waveguide approach.
Table 1 Composition of two model solutions, $\mu \mathrm{g} \mathrm{L}^{-1}$

\begin{tabular}{rrrrrrrrrrrrr}
\hline & $\mathrm{V}$ & $\mathrm{Mn}$ & $\mathrm{Co}$ & $\mathrm{Cu}$ & $\mathrm{As}$ & $\mathrm{Mo}$ & $\mathrm{Ag}$ & $\mathrm{Cd}$ & $\mathrm{Sn}$ & $\mathrm{Hg}$ & $\mathrm{Pb}$ & $\mathrm{Bi}$ \\
\hline$\# 1$ & 10 & 10 & 10 & 10 & 5 & 25 & 5 & 0.1 & 200 & 0.1 & 30 & 10 \\
$\# 2$ & 100 & 100 & 100 & 100 & 50 & 250 & 50 & 1 & 2000 & 0.5 & 100 & 100
\end{tabular}

the layers and the real distance between the upper and lower reflectors was about several nanometers (as determined by the roughness of reflectors). 125 and $250 \mu \mathrm{m}$ thickness corresponds to one and two layers of the tape accordingly. The waveguides assembled in the way described above were placed into the TXRF instrument sample compartment in an ordinary way.

\subsection{Samples}

Three different series of samples were studied. At the first stage, $\mathrm{VOSO}_{4}$ solutions were employed to establish the optimal experimental conditions (intermediate waveguide layer thickness and incident radiation angle). The most concentrated solution was prepared by the weighting method using $\mathrm{VOSO}_{4}$ $\cdot 5 \mathrm{H}_{2} \mathrm{O}$ extra pure (Vekton, St. Petersburg, Russia) and all other solutions were prepared by sequential dilution of the first one. The following vanadium concentrations were prepared: 0.01 , $0.05,0.1,0.2$, and then up to $0.9 \mu \mathrm{g} \mathrm{L}^{-1}$ with a 0.1 step (11 solutions in total).

At the second stage of the experiment, two multielemental aqueous solutions were analyzed (Table 1). These solutions were the mixtures of 12 toxic elements, the contents of which are legislatively regulated in drinking waters (\#1) and waters for domestic use (\#2). The concentrations of the elements correspond to maximum allowable concentrations according to Russian legislation. ${ }^{12}$ These two solutions were prepared using $1000 \mathrm{mg} \mathrm{L}^{-1}$ standards from Merck (Darmstadt, Germany). Vanadium was employed as an internal standard.

At the third stage of the experiment, individual aqueous solutions of $\mathrm{Cd}$ and $\mathrm{Hg}$ were analyzed in order to evaluate detection limits from the signal/noise ratio. Five concentration levels were measured for each of the elements: $0.01,0.05,0.1$, 0.5 and $1 \mu \mathrm{g} \mathrm{L}^{-1}$. The corresponding aqueous solutions were prepared from Merck standards.

The volume of the sample was $20 \mu \mathrm{L}$. The solutions were dropped onto the glass sample carrier and dried in a Binder VD53 (Binder GmbH, Germany) drying oven at $40{ }^{\circ} \mathrm{C}$ for $30 \mathrm{~min}$. After that waveguide assembling was performed and the resulting construction was introduced into the spectrometer. All measurements were repeated at least thrice and the results were averaged for further processing.

\section{Results and discussion}

At the first stage, the measurements in vanadyl solutions (0.01$1 \mu \mathrm{g} \mathrm{L}^{-1}$ ) were performed in two different geometries: with the conventional reflector and the waveguide with $125 \mu \mathrm{m}$ distance and $0.1^{\circ}$ incidence angle of excitation radiation. Signal/noise ratios (SNR) were calculated for all the samples from the 
intensity of the vanadium characteristic $\mathrm{K} \alpha$ line at $4.51 \mathrm{keV}(N)$ and the noise signal according to:

$$
\mathrm{SNR}=\frac{N}{\sqrt{N_{\mathrm{BG}}}},
$$

where $N_{\mathrm{BG}}$ is the baseline intensity under the characteristic line.

Fig. 2 shows that planar waveguide application ensures almost twofold improvement of the signal/noise ratio at low concentration levels. The detection limit was determined as a concentration of the element at which the SNR was equal to three and for the waveguide it was found to be $0.1 \mu \mathrm{g} \mathrm{L}^{-1}$, while for the conventional reflector it was as high as $0.4 \mu \mathrm{g} \mathrm{L}^{-1}$. Two parameters were optimized afterwards: incident radiation angle and the distance between upper and lower waveguide layers. For this purpose the same vanadyl solutions were measured in waveguides with distances of zero (strictly speaking it is not zero and it is determined by the roughness of glass reflectors), 125, and $250 \mu \mathrm{m}$ and then with incident angles of $0^{\circ}$ (zero angle refers to the case when incident radiation was directed right into the front edge of the waveguide, and thus the real incident angle will be determined by the beam divergence), $0.05^{\circ}$ and $0.1^{\circ}$. No improvement was observed for $250 \mu \mathrm{m}$ distance between the slides (Fig. S1 in the ESI $\dagger$ ). At $125 \mu \mathrm{m}$ distance a certain SNR increase can be observed. Although this distance is too high for multiple radiation reflection under the experimental conditions, this improvement can be attributed to additional collimation of radiation by the slides of the waveguide. Thus, scattered radiation is being reduced and the SNR increases. At "zero" (actually determined by the roughness of the glass reflectors) distance, besides the collimation effect, multiple radiation reflection can take place providing further SNR improvement. So, the optimal SNR values can be achieved at zero distance between the waveguide layers.

As a demonstration, Fig. 3 shows the vanadium spectra taken under different conditions. Fig. S2 (ESI $\dagger$ ) shows separately the

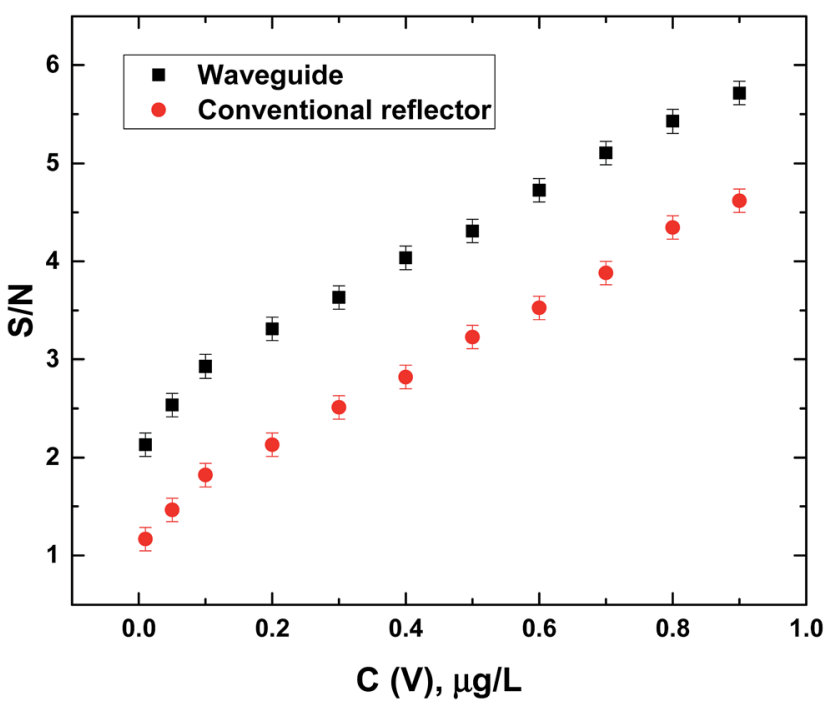

Fig. 2 Comparison of SNR for the conventional reflector and waveguide geometries determined for the vanadium characteristic $K \alpha$ line (4.51 keV).
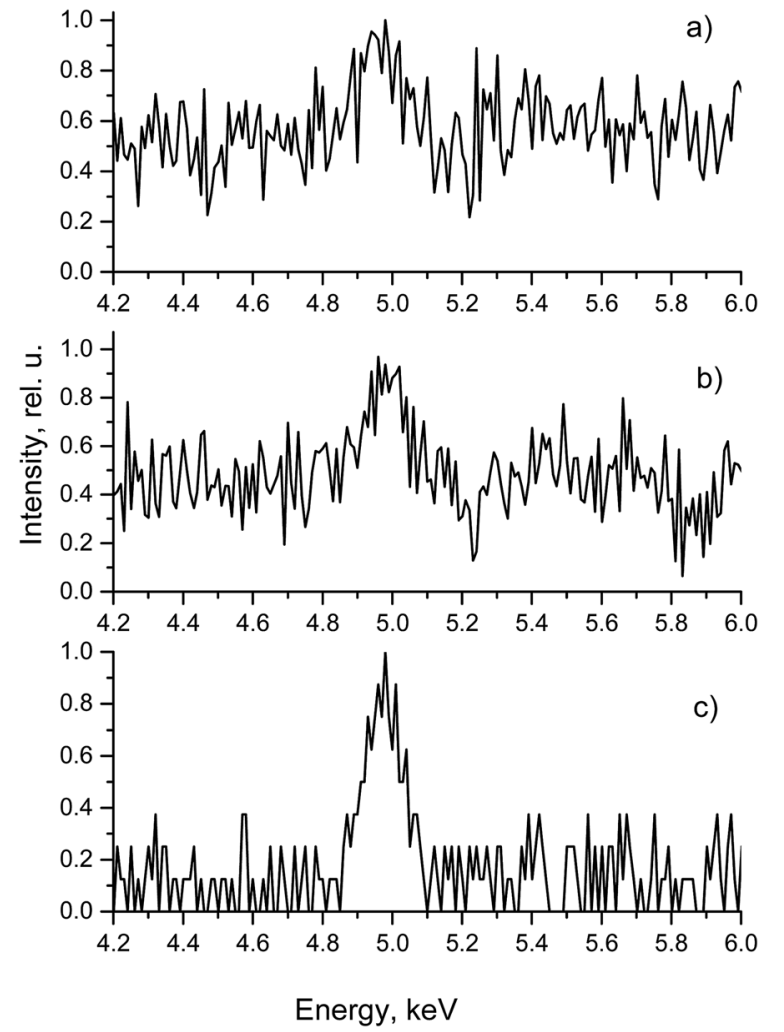

Fig. 3 Spectral regions relating to the vanadium signal $(K \alpha, K \beta)$ for 0.5 $\mu \mathrm{g} \mathrm{L}^{-1}$ vanadium solution in three set-ups: (a) original reflector at the $0.1^{\circ}$ incident angle; (b) waveguide with $125 \mu \mathrm{m}$ distance between the reflectors at the $0.1^{\circ}$ incident angle; (c) waveguide with "zero" distance between reflectors at the $0^{\circ}$ incident angle.

intensity of the vanadium $\mathrm{K} \alpha$ line and the corresponding background signal. It can be seen from Fig. $\mathrm{S} 2 \uparrow$ that at 125 and $250 \mu \mathrm{m}$ distances the signal itself remains almost constant, while there is a certain decrease in the background. When the distance becomes "zero", both the signal and the background decrease due to the reduction of radiation quantity; however this should not affect the SNR value. At the same time the SNR increases due to multiple reflections in the waveguide leading to signal growth. Fig. S3† shows that the incident angle at "zero" distance providing the best SNR is the $0^{\circ}$ angle. More than twofold improvement of SNR was observed under these conditions. The influence of the incident angle was smaller than that of the distance. The vanadium detection limit under optimized conditions was $0.01 \mu \mathrm{g} \mathrm{\textrm {L } ^ { - 1 }}$.

At the second stage of the experiment, two model solutions containing the mixtures of 12 toxic elements at the concentration levels prescribed by local legislation for drinking waters (\#1) and waters for domestic use (\#2) were analyzed. Both the conventional reflector and proposed waveguide were employed for the measurements. The calculation of elemental content was done using the internal standard method with vanadium as a standard. Additionally the content of elements in model mixtures was confirmed by atomic emission spectroscopy with an inductively coupled plasma (ICP-AES) Shimadzu ICPE-9000. The results are given in Table 2 . The TXRF-PW methodology 
Table 2 Content of the studied elements in model mixtures determined by ICP-AES, TXRF with the conventional reflector (CR) and TXRF with the planar waveguide (PW), $n=3, p=0.95$

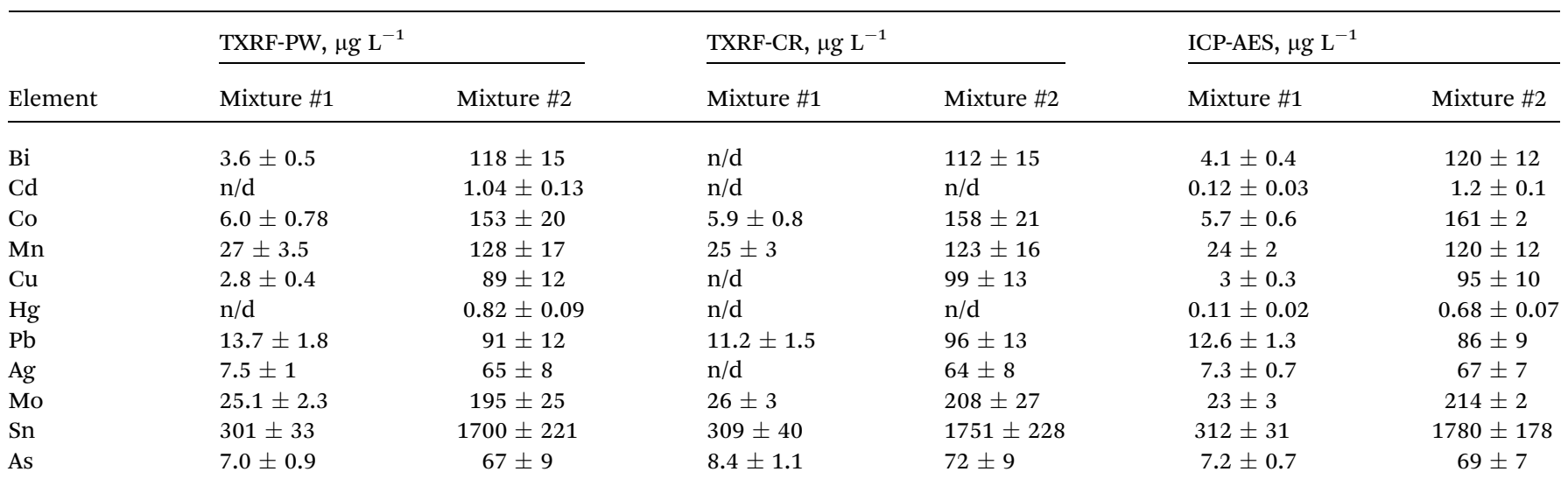

allows for reliable quantification of all the elements in model mixture \#2 (domestic waters), while TXRF-CR fails to quantify $\mathrm{Cd}$ and $\mathrm{Hg}$. In mixture \#1 (drinking waters), CR was unable to determine $\mathrm{Bi}, \mathrm{Cd}, \mathrm{Cu}, \mathrm{Hg}$, and $\mathrm{Ag}$, while $\mathrm{PW}$ could help determining almost all the studied elements except $\mathrm{Cd}$ and $\mathrm{Hg}$. It is worth noting that this significant improvement of analysis was achieved by very simple means, without any sample manipulation, like e.g. preliminary concentration. A separate study was performed to establish the detection limits of the PW methodology towards $\mathrm{Cd}$ and $\mathrm{Hg}$. The detection limit was determined as a concentration of the element at which the SNR was equal to three. The $L \alpha$ lines of the elements were employed $3.13 \mathrm{keV}$ for $\mathrm{Cd}$ and $9.99 \mathrm{keV}$ for $\mathrm{Hg}$ ). In the case of $\mathrm{Hg}$ the achieved detection limit was $0.13 \mu \mathrm{g} \mathrm{L}^{-1}$, which is higher than that of one of the best values reported in the literature for a sophisticated electrochemical enrichment procedure $\left(0.004 \mu \mathrm{g} \mathrm{L}^{-1}\right.$ (ref. 13)). However it is better than e.g. detection limits obtained with preconcentration on silver nanoparticles $\left(0.55 \mu \mathrm{g} \mathrm{L}^{-1}\right.$ (ref. 8)). The observed detection limit of Cd was $0.12 \mu \mathrm{g} \mathrm{L}^{-1}$, which is better than the values reported in the literature for dispersive micro solid-phase extraction, using multiwalled carbon nanotubes (MWCNTs) as solid sorbents $\left(1 \mu \mathrm{g} \mathrm{L} \mathrm{L}^{-1}\right.$ (ref. 14)). However, this result is somewhat worse than the Cd detection limit with the dispersive liquid-liquid microextraction approach $(0.04 \mu \mathrm{g}$ $\mathrm{L}^{-1}$ (ref. 15)). It must be pointed out that the PW approach suggested in this study does not require complex sample preconcentration techniques and all the measurements are performed with the sample as is. However, pre-concentration can still be an important part of the TXRF measurement protocol, especially when matrix interference has to be eliminated or various forms of the same element have to be analyzed.

\section{Conclusion}

A very simple procedure based on a planar waveguide technique was suggested in this study to improve the sensitivity of the TXRF method perceptibly. The placement of a sample directly onto a planar waveguide allows for increasing photon density in the sample and for minimizing scattered radiation. The application of this approach leads to a considerable improvement in the signal-to-noise ratio in a spectrum. The advantages of the proposed method were demonstrated for metal quantification in aqueous solutions of complex composition. The observed detection limits for the studied elements were significantly lower than those obtained in a traditional way. We see a very high potential of the sample-in-a-waveguide approach for the development of simple X-ray optics without complex collimation and monochromatization devices employed in traditional TXRF, since the conditions for total reflection can be formed directly in a waveguide.

\section{Acknowledgements}

This work was partially financially supported by the Government of Russian Federation (Grant 074-U01).

\section{References}

1 N. V. Alov, Inorg. Mater., 2011, 47, 1487.

2 T. Y. Cherkashina, S. V. Panteeva and G. V. Pashkova, Spectrochim. Acta, Part B, 2014, 99, 59.

3 O. T. Butler, W. R. L. Cairns, J. M. Cook and C. M. Davidson, J. Anal. At. Spectrom., 2016, 31, 35.

4 N. Szoboszlai, Z. Polgári, V. G. Mihucz and G. Záray, Anal. Chim. Acta, 2009, 633, 1.

5 E. Marguí, M. Sagué, I. Queralt and M. Hidalgo, Anal. Chim. Acta, 2013, 786, 8.

6 N. Kallithrakas-Kontos and V. Hatzistavros, X-Ray Spectrom., 2009, 38, 229.

7 B. Staniszewski and P. Freimann, Spectrochim. Acta, Part B, 2008, 63, 1333.

8 V. Romero, I. Costas-Mora, I. Lavilla and C. Bendicho, J. Anal. At. Spectrom., 2014, 29, 696.

9 M. A. Kumakhov, X-Ray Spectrom., 2000, 29, 343.

10 V. K. Egorov and E. V. Egorov, Thin Solid Films, 2001, 398399, 405. 
11 R. Soufli, J. C. Robinson, M. Fernández-Perea, E. Spiller, N. F. Brejnholt, M. A. Descalle, M. J. Pivovaroff and E. M. Gullikson, Springer Proc. Phys., 2016, 169, 331.

12 Russian Federation SanPiN (Sanitary Rules and Norms) 2.1.4.1074-01. Drinking water, Hygienical requirements to the water quality in centralized systems of water supply, Quality control.
13 A. Ritschel, P. Wobreauschek, E. Chinea, F. Grass and Ch. Fabjan, Spectrochim. Acta, Part B, 1999, 54, 1449.

14 K. Kocot, B. Zawisza, E. Marguí, I. Queralt, M. Hidalgo and R. Sitko, J. Anal. At. Spectrom., 2013, 28(2013), 736.

15 E. Marguí, I. Queralt and M. Hidalgo, J. Anal. At. Spectrom., 2013, 28, 266. 